\title{
Primaquine-thiazolidinones block malaria transmission and development of the liver exoerythrocytic forms
}

\author{
Anna Caroline C. Aguiar ${ }^{1,2,3}$, Flávio Jr. B. Figueiredo ${ }^{1}$, Patrícia D. Neuenfeldt ${ }^{4}$, Tony H. Katsuragawa ${ }^{5}$, \\ Bruna B. Drawanz ${ }^{4}$, Wilson Cunico ${ }^{4}$, Photini Sinnis ${ }^{3}$, Fidel Zavala ${ }^{3}$ and Antoniana U. Krettli ${ }^{1,2^{*}}$
}

\begin{abstract}
Background: Primaquine is an anti-malarial used to prevent Plasmodium vivax relapses and malaria transmission. However, PQ metabolites cause haemolysis in patients deficient in the enzyme glucose-6-phosphate dehydrogenase (G6PD). Fifteen PQ-thiazolidinone derivatives, synthesized through one-post reactions from primaquine, arenealdehydes and mercaptoacetic acid, were evaluated in parallel in several biological assays, including ability to block malaria transmission to mosquitoes.

Results: All primaquine derivatives (PQ-TZs) exhibited lower cell toxicity than primaquine; none caused haemolysis to normal or G6PD-deficient human erythrocytes in vitro. Sera from mice pretreated with the test compounds thus assumed to have drug metabolites, caused no in vitro haemolysis of human erythrocytes, whereas sera from mice pretreated with primaquine did cause haemolysis. The ability of the PQ-TZs to block malaria transmission was evaluated based on the oocyst production and percentage of mosquitoes infected after a blood meal in drug pre-treated animals with experimental malaria caused by either Plasmodium gallinaceum or Plasmodium berghei; four and five PQ-TZs significantly inhibited sporogony in avian and in rodent malaria, respectively. Selected PQ-TZs were tested for their inhibitory activity on P. berghei liver stage development, in mice and in vitro, one compound (4m) caused a 3-day delay in the malaria pre-patent period.
\end{abstract}

Conclusions: The compound $4 \mathrm{~m}$ was the most promising, blocking malaria transmissions and reducing the number of exoerythrocytic forms of $P$. berghei (EEFs) in hepatoma cells in vitro and in mice in vivo. The same compound also caused a 3-day delay in the malaria pre-patent period.

Keywords: Malaria, Thiazolidinones, Sporogony, Plasmodium berghei, Plasmodium gallinaceum, Blocking malaria transmission, Exoerythrocytic stages, sporozoites

\section{Background}

Plasmodium vivax is the most widespread parasite in Asia and Americas, with three billion people estimated to be at risk of vivax malaria [1-3]. To improve the malaria control programmes and decrease malaria mortality worldwide, the World Health Organization recommends the use of primaquine (PQ), which is used to prevent $P$. vivax relapses [1]. PQ is also active

\footnotetext{
*Correspondence: akrettli@cpqrr.fiocruz.br

1 Centro de Pesquisas René Rachou-Fiocruz, Av. Augusto de Lima 1715, Belo Horizonte, MG 30190-002, Brazil

Full list of author information is available at the end of the article
}

against gametocytes; thus, it is used to block malaria transmission in areas approaching malaria elimination and/or facing artemisinin resistance where it is expected that transmission-blocking strategies will help to slow down the spread of resistant parasites [4]. A single $0.75 \mathrm{mg} / \mathrm{kg}$ dose of PQ is effective as a gametocytocidal agent [1]. However, PQ has restrictions because it is poorly tolerated and its metabolites cause haemolysis in patients with glucose-6-phosphate dehydrogenase (G6PD) deficiency [5]. PQ is currently the only agent approved for elimination of hypnozoites, 
the dormant liver stages of $P$. vivax that cause the late relapses [1].

The discovery that PQ-imidazolidin-4-one derivatives (Fig. 1a) exhibit transmission-blocking anti-malarial activity [6] has led to the exploration of the aliphatic terminal amino group of $\mathrm{PQ}$ as a precursor to the synthesis of thiazolidinones (TZ) (Fig. 1b). The thiazolidinone heterocyclic class has wide applications in the medicinal chemistry field [7] with some thiazolidinone and thiazinanone-chloroquine analogs displaying higher activity against Plasmodium falciparum than chloroquine (CQ) [8].

Aiming to find candidates less toxic than $\mathrm{PQ}$, a total of 15 PQ thiazolidinone derivatives (PQ-TZs) were synthesized through modification of the amino-terminal group [9] and evaluated for: (i) in vitro haemolytic activity against G6PD normal or deficient erythrocytes; (ii) toxicity in vitro to hepatoma and kidney cells; (iii) blocking effect on the malaria sporogonic cycle in mosquitoes and; (iv) ability to interfere with the development of Plasmodium berghei liver stages in vivo and in vitro. In all assays, PQ was used as the control drug.

\section{Methods}

\section{Chemical synthesis}

The target compounds (Fig. 2) were prepared as previously described [9]. Briefly, the 2-aryl-3-[4-(6-methoxyquinolin-8-amino) pentyl] thiazolidin-4-one derivatives (PQ-TZs) 4b-p were synthesized by multicomponent one-pot reactions from PQ diphosphate $1, N, N$-diisopropylethylamine (DIPEA), arenealdehydes $2 \mathrm{~b}-\mathrm{p}$ and excess of the mercaptoacetic acid 3 in refluxing toluene for $2-4 \mathrm{~h}$. Primaquine (PQ), used as a control in all experiments, was primaquine bisphosphate $(>98 \%)$ from Sigma). Doses were calculated using the molecular weight of the PQ-salt $455.34 \mathrm{~g} / \mathrm{mol}$.

\section{Human and animal ethical approvals}

Human erythrocytes, normal or G6PD-deficien were collected from blood donors under the auspices of the Ethics Committee of "Centro de Pesquisa em Medicina Tropical de Rondônia-CEPEM" (CAAE-007 59912.0.0000.0011; October 9,2012 ) as described in a previous publication [10]. The written consent was obtained for each new sample used in the present research.<smiles>[R7]C1C(=O)N(CCCC(C)Nc2cc(OC)cc3cccnc23)C([R7])([R])N1[R]</smiles><smiles>[R][I-]1=C=CC=CC1C1SCC(=O)N1CCCC(C)Nc1cc(OC)cc2cccnc12</smiles>

a

b

Fig. 1 General structures of a PQ-imidazolidinones and $\mathbf{b}$ PQ-thiazolidinones (PQ-TZs)

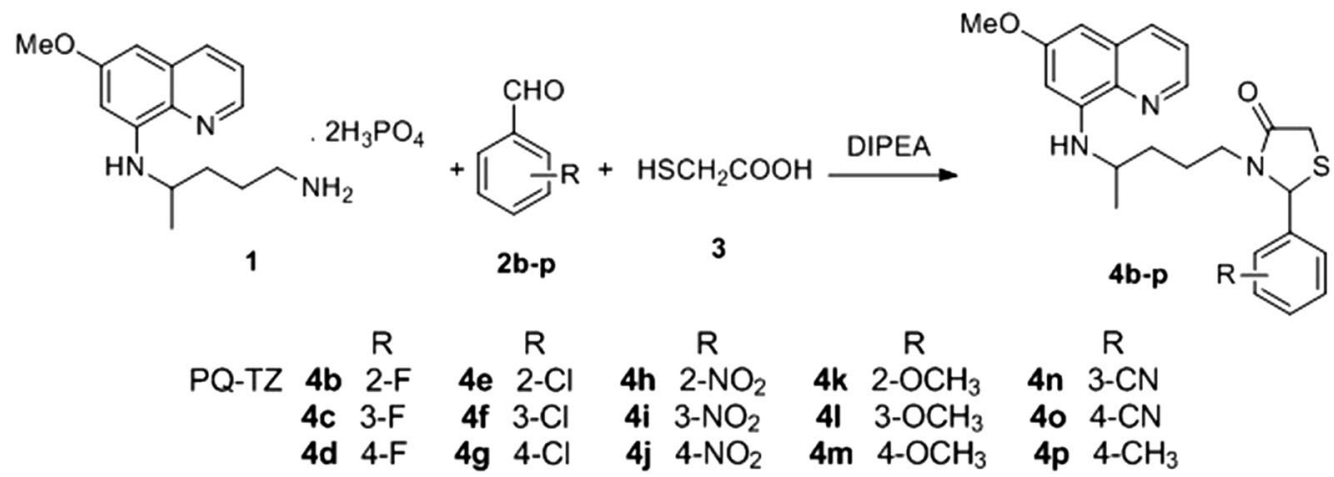

Fig. 2 Synthetic route for PQ-TZs $4 b-4 p$. Reaction conditions were as described [9] 
The animal studies were approved by the Ethics Committee at the Instituto Osvaldo Cruz (FIOCRUZ, CEUA LW-23/13), and, by the Johns Hopkins University Institutional Animal Care Committee (protocol number MO13H123). Mice and chickens were anaesthesized with acepromazine $2.5 \mathrm{mg} / \mathrm{kg}$ then sacrificed by cervical dislocation. The parasitaemia was monitored in each animal starting 2 days after parasite inoculation, to determine the malaria pre-patent period (in mice subjected to sporozoite infections). The physical conditions of the animals were evaluated daily. Mice were sacrificed 3 days after the beginning of the experiment for liver stage evaluation; in other experiments, they were anaesthesized with acepromazine $2.5 \mathrm{mg} / \mathrm{kg}$ then sacrificed soon after the malaria symptoms appeared, such as anaemic blood, weight loss, ruffled fur, abnormal postural responses, reduced reflexes and reduced grip strength, coma, and convulsions. Infected chicken with an early infection were sacrificed immediately after they were used to blood-feed the mosquitoes twice in the same experiment, thus before the malaria symptoms began.

\section{In vitro cytotoxicity assay}

The cytotoxicity of PQ and PQ-TZ compounds was assessed against cultures of: (i) a human hepatoma cell line (HepG2), received from the New University of Lisbon; (ii) a mouse hepatocyte cell line (HEPA 1-6), purchased from ATCC; and (iii) a kidney cell line from Buffalo Green Monkey Kidney (BGM) kindly provided by the Federal University of Minas Gerais. Cells were cultured in $75-\mathrm{cm}^{2}$ sterile flasks in RPMI 1640 supplemented with $10 \%$ heat-inactivated fetal calf serum and $40 \mathrm{mg} / \mathrm{L}$ gentamicin, under $5 \% \mathrm{CO}_{2}$ at $37{ }^{\circ} \mathrm{C}$. The confluent cell monolayer was trypsinized, distributed in a flat-bottomed 96-well plate $\left(5 \times 10^{3}\right.$ cells/well), then incubated for $18 \mathrm{~h}$ at $37{ }^{\circ} \mathrm{C}$ for cell adherence, as previously described [11]. The compounds were diluted in RPMI at a final concentration of $0.2 \%$ DMSO, and $20 \mu \mathrm{L}$ were added at various concentrations up to $1000 \mu \mathrm{g} / \mathrm{ML}$. The same diluent solution (RPMI + 1\% DMSO) was used as a control in the non-treated cells. Cells were incubated for $24 \mathrm{~h}$ under $5 \% \mathrm{CO}_{2}$ at $37{ }^{\circ} \mathrm{C}$, then incubated with MTT [3-(4,5-dimethylthiazol-2-yl)-2,5-diphenyltetrazolium bromide] solution $(5 \mathrm{mg} / \mathrm{mL} ; 20 \mu \mathrm{L} /$ well $)$ for $3 \mathrm{~h}$, in the same culture conditions. The supernatant was removed, $100 \mu \mathrm{L}$ of DMSO was added to solubilize the formazan crystals formed, and the optical density was determined at 570 and $630 \mathrm{~nm}$ (background) (SpectraMax340PC ${ }^{384}$, Molecular Devices). Cell viability was expressed as the percentage of the control absorbance in the untreated cells after subtracting the appropriate background. The minimum lethal dose for $50 \%$ of the cells $\left(M_{L} D_{50}\right)$ was determined as previously described [12]. A toxicity ratio between the $\mathrm{MDL}_{50}$ of $\mathrm{PQ}-\mathrm{TZ}$ and $\mathrm{PQ}$ was calculated (PQ-TZ/PQ) for each drug.

\section{In vivo cytotoxicity assay}

Selected compounds (4b, 4c, 4g, 4h, 4m, 4o, 4p) and PQ were administered to normal mice orally at a single dose. Different doses were evaluated (100, 50 and $25 \mathrm{mg} /$ $\mathrm{kg}$ ). Animal survival was observed during the following 30 days as described [13]. When the mice developed malaria, they were euthanized soon after the first symptoms appeared, as described above. The compounds were diluted in RPMI with $3 \%$ of DMSO; the control group was treated with the same vehicle.

\section{Plasmodium berghei and Plasmodium gallinaceum sporogonic assays}

Mice were inoculated intraperitoneally (i.p.) with $10^{6} P$. berghei (ANKA strain) infected red blood cells. Parasitaemia was monitored using Giemsa-stained blood smear and examined for the presence of gametocytes. When present, a blood sample was examined to determine the presence of exflagellating gametocytes. Anopheles stephensi mosquitoes were blood-feed from mice whose blood showed more than two exflagellating centres per field. The same infected mice were used twice, at time $0 \mathrm{~h}$, before drug administration (control), and $2 \mathrm{~h}$ after receiving the drug by gavage. The drug was administered right after the first feeding. The control and experimental mosquito groups were dissected 12 days after the blood meal in mice. Midguts were removed, stained with $0.5 \%$ mercurochrome, and oocysts were counted by light microscopy. Inhibition of sporogony was calculated based on the oocyst numbers in the control mosquitoes $(0 \mathrm{~h})$ considered as $100 \%$ infection, and in the test mosquitoes blood-fed $2 \mathrm{~h}$ after drug treatment.

Chickens (1 week old) were inoculated with P. gallinaceum-infected erythrocytes. When parasitaemia was increasing but still below 10\% they were fed-upon by Aedes fluviatilis mosquitoes, which were dissected at days 6-7 after the infectious blood meal. The control mosquito group was exposed to the infected chickens before drug treatment (time $0 \mathrm{~h}$ ); the test animals were fed by mosquitoes twice, at time $0 \mathrm{~h}$ (control) and 4-6 $\mathrm{h}$ after drug treatment, as described previously [14, 15].

In all cases, PQ-TZ derivatives were tested at $50-100 \mathrm{mg} / \mathrm{kg}$ while $\mathrm{PQ}$, which is more toxic, was tested at $15 \mathrm{mg} / \mathrm{kg}$ (non-toxic). PQ was diluted in water and the PQ-TZs were diluted in RPMI with $3 \%$ of DMSO, the control group was tread with the same vehicle.

The criteria used to evaluate the drug ability to block malaria sporogony was based on examination of 20 mosquitoes in each group. The percentage of infected mosquitoes (prevalence) and the mean number of oocysts per 
group (intensity) were calculated. A compound was considered partially active when the number of oocysts and mosquitoes infected was reduced by at least $50 \%$, in comparison to the non-treated control, and as active when $100 \%$ reduction occurred.

\section{In vitro liver stage development of Plasmodium berghei}

Plasmodium berghei (ANKA) sporozoites freshly isolated from salivary glands of infected An. stephensi mosquitoes were counted in a haemocytometer and diluted to the appropriated concentration. Ten thousand sporozoites in $0.4 \mathrm{~mL}$ of complete Dulbecco modified Eagle medium (DMEM) supplemented with $10 \%$ foetal bovine serum (FBS) and $40 \mathrm{mg} / \mathrm{L}$ of penicillin/streptomycin, were added to each well of a 6-well culture plate containing semi-confluent Hepa 1-6 cells seeded 1 day earlier. Drugs at 10,1 and $0.1 \mu \mathrm{M}$, freshly diluted in $0.05 \%$ DMSO were added to the plates $3 \mathrm{~h}$ after sporozoite infection of cell cultures. The vehicle was used as a control $(0.05 \%$ DMSO). The cultures were allowed to grow at $37{ }^{\circ} \mathrm{C}$ in $5 \% \mathrm{CO}_{2}$ for $48 \mathrm{~h}$. The culture medium was changed every $12 \mathrm{~h}$, and fresh compounds were added at the same concentration, to maintain inhibitor pressure throughout the growth period. After $48 \mathrm{~h}$, the cells were fixed with $4 \%$ paraformaldehyde, permeabilized with cold methanol overnight, blocked with $1 \%$ bovine serum albumin (BSA) in PBS for $2 \mathrm{~h}$, then incubated for $1 \mathrm{~h}$ with monoclonal antibody 3D11 [16], directed against the circumsporozoite protein of $P$. berghei. The plates were washed three times with PBS, $0.05 \%$ Tween 20 (PBST), incubated with secondary antibody coupled to Alexa 594 (Life Technologies) for $1 \mathrm{~h}$, washed three times with PBST, and mounted using prolong reagent containing DAPI (Life Technologies). Images of liver-stage parasites were captured using a fluorescence microscope (Nikon 90i). The Pro-Plus program (Media Cybernetics) was used to measure the size of the liver-stage parasites [16].

\section{In vivo parasite liver load assay in rodent malaria}

Mice were drug-treated by oral route, on days $-3,2,1$ and 0 , where day 0 corresponds to the day of sporozoite infection by intravenous route. The parasite liver load was evaluated $42 \mathrm{~h}$ after sporozoite inoculation, when the mice were euthanized, their livers were harvested, and total RNA extracted using Trizol reagent (Thermo Fisher Scientific, MA, USA). Reverse transcription with $4 \mu \mathrm{g}$ of RNA was performed to obtain cDNA. In a real-time PCR mix of $50 \mu \mathrm{L}$, a cDNA equivalent of $0.5 \mu \mathrm{g}$ RNA was used. The real-time PCR mix also contained primers specific for the $P$. berghei $18 \mathrm{~S}$ rRNA and SYBR green dye. Real-time PCR was performed in a Bio-Rad I cycler, and the copy numbers were calculated using a known amount of a standard plasmid having the amplification target sequence [17]. Parasite growth inhibition was calculated by dividing the $18 \mathrm{~S}$ rRNA copy number of the experimental group by that of the untreated control group.

\section{Prepatent period of malaria and survival assays}

Mice were treated with $4 \mathrm{M} \mathrm{PQ-TZ} \mathrm{at} \mathrm{a} \mathrm{dose} \mathrm{of} 50 \mathrm{mg} /$ $\mathrm{kg}$ by oral route on days $-3,-2,-1$ and 0 , where day 0 corresponds to the day of sporozoite inoculation. Ten thousand salivary gland sporozoites were inoculated by intravenous route and the parasitaemia and survival were followed for 30 days. A total of 5 mice were used per group. As described above, the mice were anaesthesized with acepromazine $2.5 \mathrm{mg} / \mathrm{kg}$, then sacrificed soon after the malaria symptoms appeared.

\section{In vitro haemolysis assay}

Experiments were performed with both human and mouse erythrocytes. Human erythrocytes (2\% haematocrit) from normal or G6PD deficient donors were incubated with test and control compounds, diluted in a $0.2 \%$ (v/v) DMSO solution to $15-1000 \mu \mathrm{g} / \mathrm{mL}$, at $37{ }^{\circ} \mathrm{C}$ for 2 and $24 \mathrm{~h}$ in a shaking water bath. To look at whether metabolites of the PQ-TZs had haemolytic properties, blood samples were taken from the mice, by retro-orbital blood collection, $15 \mathrm{~min}$ to $2 \mathrm{~h}$ after the oral treatment of the animals with PQ $(15 \mathrm{mg} / \mathrm{kg})$, with the PQ-TZ $(100 \mathrm{mg} / \mathrm{kg})$; blood from not treated animals were used as a control. Twenty microliter of serum were incubated with human erythrocytes, during $2 \mathrm{~h}$ at $37^{\circ} \mathrm{C}$. The mixtures were centrifuged at $1000 \mathrm{~g}$ for $10 \mathrm{~min}$, and the absorbance of the supernatants was measured at $540 \mathrm{~nm}$ in an ELISA plate reader (SpectraMax340PC384, Molecular Devices). The haemolytic rate was calculated using $0.05 \%$ saponin, as positive control for haemolysis of human erythrocytes, considered as $100 \%$ [18].

The diagnosis of G6PD deficiency was confirmed using a technique based on the principle that haemoglobin oxidized to methaemoglobin by the action of sodium nitrite is converted by the enzyme in the presence of methylene blue [19]. The final brown colour demonstrates a sample positive for G6PD deficiency, while a bright red colour is indicative of a normal sample. In the present study, the RBC samples used were of four patients with G6PD deficiency first diagnosed by one of the authors (THK), as described before [10].

\section{Results}

\section{Primaquine derivatives are not as toxic as primaquine}

To evaluate the toxicity of PQ derivatives on nucleated cells in vitro, HepG2 cells, a human hepatoma cell line, and a monkey kidney cell line (BGM), were incubated with the compounds for $24 \mathrm{~h}$. Cell viability was measured by MTT, a colorimetric assay for assessing cell metabolic 
Table 1 Cytotoxicity of 15 primaquine derivatives (PQ-TZ $4 \mathrm{~b}$ to $4 p$ ) to human hepatoma cells (HepG2) and monkey kidney cells (BGM), as compared to primaquine

\begin{tabular}{|c|c|c|c|c|c|}
\hline \multirow[t]{2}{*}{ Compound } & \multirow[t]{2}{*}{$\mathbf{R}$} & \multicolumn{2}{|c|}{$\begin{array}{l}\text { Cytotoxicity }\left(\mathrm{MDL}_{50}\right. \\
\text { in } \mu \mathrm{M})\end{array}$} & \multicolumn{2}{|c|}{$\begin{array}{l}\text { Toxicity ratios } \\
\left(\mathrm{MDL}_{50}\right) \\
\text { PQ-TZ/PQ }\end{array}$} \\
\hline & & HepG2 & BGM & HepG2 & BGM \\
\hline $4 b$ & $2-F$ & NT & NT & - & - \\
\hline $4 c$ & $3-F$ & $1302 \pm 108$ & $550 \pm 43$ & 4.4 & 2.7 \\
\hline 4d & $4-\mathrm{F}$ & $\geq 6831$ & $\geq 6831$ & 23.3 & 33.8 \\
\hline $4 e$ & $2-\mathrm{Cl}$ & $\geq 2193$ & $\geq 2193$ & 9.4 & 10.8 \\
\hline $4 f$ & $3-\mathrm{Cl}$ & $641 \pm 31$ & $252 \pm 24$ & 2.7 & 1.2 \\
\hline $\mathbf{4 g}$ & $4-\mathrm{Cl}$ & $3984 \pm 116$ & NT & 17 & - \\
\hline 4h & $2-\mathrm{NO}_{2}$ & $1463 \pm 105$ & $1312 \pm 145$ & 6.3 & 6.5 \\
\hline $4 i$ & $3-\mathrm{NO}_{2}$ & $536 \pm 17$ & $523 \pm 210$ & 2.3 & 2.6 \\
\hline $4 j$ & $4-\mathrm{NO}_{2}$ & $\geq 6651$ & $\geq 6651$ & 28.5 & 32.9 \\
\hline $\mathbf{4 k}$ & $2-\mathrm{OCH}_{3}$ & $\geq 6833$ & $\geq 6833$ & 29.3 & 33.8 \\
\hline 41 & $3-\mathrm{OCH}_{3}$ & $\geq 6651$ & $\geq 6651$ & 28.5 & 32.9 \\
\hline $4 m$ & $4-\mathrm{OCH}_{3}$ & $\geq 6644$ & $\geq 6644$ & 28.5 & 32.9 \\
\hline $4 n$ & $3-C N$ & $\geq 2242$ & $\geq 2242$ & 9.6 & 11.0 \\
\hline 40 & $4-C N$ & $\geq 6726$ & $\geq 6726$ & 28.8 & 33.3 \\
\hline $4 p$ & $4-\mathrm{CH}_{3}$ & $\geq 6651$ & $\geq 6651$ & 28.5 & 32.9 \\
\hline Primaquine & & $233 \pm 5$ & $202 \pm 35$ & - & - \\
\hline
\end{tabular}

Drug concentration that killed $50 \%$ of cells using the MTT assay as a readout NT not tested

Table 2 Hemolysis (\%) of normal and G6PD deficient erythrocytes after $2 \mathrm{~h}$ incubation with sera from mice dosed with primaquine $(15 \mathrm{mg} / \mathrm{kg}$ ) or PQTZ (100 mg/kg)

\begin{tabular}{|c|c|c|c|c|c|}
\hline \multirow[t]{2}{*}{$\begin{array}{l}\text { Erythrocyte } \\
\text { samples }\end{array}$} & \multicolumn{5}{|c|}{$\begin{array}{l}\text { Hemolysis (\%) by time between mouse dosage } \\
\text { and serum collection }\end{array}$} \\
\hline & $15 \mathrm{~min}$ & $30 \mathrm{~min}$ & $45 \mathrm{~min}$ & $60 \mathrm{~min}$ & $120 \mathrm{~min}$ \\
\hline \multicolumn{6}{|l|}{ Primaquine } \\
\hline Normal & $0 \pm 0$ & $22 \pm 12^{* *}$ & $32 \pm 10^{* *}$ & $30 \pm 16^{* *}$ & $10 \pm 11^{* *}$ \\
\hline $\begin{array}{l}\text { G6PD defi- } \\
\text { cient }\end{array}$ & $0 \pm 0$ & $48 \pm 2^{* *}$ & $54 \pm 12^{* *}$ & $43 \pm 22^{* *}$ & $36 \pm 13^{* *}$ \\
\hline \multicolumn{6}{|c|}{ PQTZS $(\mathbf{4 b}, \mathbf{4 c}, \mathbf{4 d}, \mathbf{4 e}, \mathbf{4 f}, \mathbf{4 g}, \mathbf{4 h}, \mathbf{4 i}, \mathbf{4 j}, \mathbf{4 k}, \mathbf{4 l}, \mathbf{4 m}, \mathbf{4 n}, \mathbf{4 o}$ and $\mathbf{4 p})$} \\
\hline Normal & $0 \pm 0$ & $0 \pm 0$ & $0 \pm 0$ & $0 \pm 0$ & $0 \pm 0$ \\
\hline $\begin{array}{l}\text { G6PD defi- } \\
\text { cient }\end{array}$ & $0 \pm 0$ & $0 \pm 0$ & $0 \pm 0$ & $0 \pm 0$ & $0 \pm 0$ \\
\hline \multicolumn{6}{|l|}{ Not treated } \\
\hline Normal & $0 \pm 0$ & $0 \pm 0$ & $0 \pm 0$ & $0 \pm 0$ & $0 \pm 0$ \\
\hline $\begin{array}{l}\text { G6PD defi- } \\
\text { cient }\end{array}$ & $0 \pm 0$ & $0 \pm 0$ & $0 \pm 0$ & $0 \pm 0$ & $0 \pm 0$ \\
\hline
\end{tabular}

Mean and standard deviation of three different animals

** Statistical differences as compared to not treated controls are indicated by an asterisk ( $p<0.05$, by Mann-Whitney test)

activity and the drug concentration that killed $50 \%$ of the cells $\left(\mathrm{MDL}_{50}\right)$ was calculated. The $\mathrm{MDL}_{50}$ value of the PQ derivatives was compared with $\mathrm{PQ}$, showing that all 14
PQ-TZ tested were less toxic than PQ; the compounds $4 \mathrm{~d}$, $4 \mathrm{j}, 4 \mathrm{k}, 4 \mathrm{l}, 4 \mathrm{~m}, 4 \mathrm{o}$ and $4 \mathrm{p}$ were 20 times less toxic than PQ in HepG2 and over $30 \times$ less toxic to BGM cells (Table 1).

The toxicity of the PQ derivatives was also evaluated on human erythrocytes, aiming to see if these compounds have different levels of toxicity to normal erythrocytes compared to G6PD deficient erythrocytes. Different concentrations $(15-1000 \mu \mathrm{g} / \mathrm{mL})$ of PQ-TZs $(4 \mathrm{~b}, 4 \mathrm{c}, 4 \mathrm{~d}$, $4 \mathrm{e}, 4 \mathrm{f}, 4 \mathrm{~g}, 4 \mathrm{~h}, 4 \mathrm{i}, 4 \mathrm{j}, 4 \mathrm{k}, 4 \mathrm{l}, 4 \mathrm{~m}, 4 \mathrm{n}, 4 \mathrm{o}$ and $4 \mathrm{p}$ ) were incubated with human erythrocytes, and the rate of haemolysis evaluated. These compounds were not haemolytic to normal erythrocytes or to G6PD deficient erythrocytes, while PQ was haemolytic, even at the lowest dose tested (Table 2). In addition, sera from drug-treated mice were tested for haemolysis, to determine if these PQ-TZs produce toxic metabolites as PQ does. Sera were collected between $15 \mathrm{~min}$ up to $2 \mathrm{~h}$ after treatment of mice with PQ $(15 \mathrm{mg} / \mathrm{kg})$ or with PQ-TZ (100 mg/kg), and incubated with the normal or G6PD deficient erythrocytes for $2 \mathrm{~h}$ (Table 2).

All mice (total of three mice per group) survived until the end of the experiment. After the blood collection, they were anaesthesized with acepromazine $2.5 \mathrm{mg} / \mathrm{kg}$ then sacrificed by cervical dislocation. Only sera from PQ-treated mice caused haemolysis: about $48 \%$ haemolysis was observed when sera were collected $30 \mathrm{~min}$ following treatment. Sera collected $120 \mathrm{~min}$ after treatment with PQ had a lower haemolysis rate, likely from the lower concentration of circulating toxic metabolites.

The in vivo toxicity of PQ and PQ-TZs compounds was tested in mice receiving the drugs administered by gavage, 5 mice per group. PQ in a single dose of 100 or $50 \mathrm{mg} / \mathrm{kg}$ was fatal on the second day for all mice. The $25 \mathrm{mg} / \mathrm{kg}$ dose was not toxic and all mice survived for up to 30 days. Compounds $4 \mathrm{c}, 4 \mathrm{~g}, 4 \mathrm{~m}$ and $4 \mathrm{o}$ administered as a single dose of $1000 \mathrm{mg} / \mathrm{kg}$ caused no death within the 30 days of observation. The compounds $4 \mathrm{~b}, 4 \mathrm{~m}$ and $4 \mathrm{p}$ were given in a single dose of $500 \mathrm{mg} / \mathrm{kg}$, and all mice survived for up to 30 days, the last day of observation. The animals were anaesthetized with acepromazine $2.5 \mathrm{mg} / \mathrm{kg}$ and sacrificed by cervical dislocation on day 30th (end of the experiment).

\section{Primaquine derivatives block Plasmodium transmission to mosquitoes}

Primaquine PQ-TZ derivatives were tested for their ability to inhibit oocyst formation in both rodent and bird malaria models. An. stephensi mosquitoes were allowed to feed on $P$. berghei-infected mice immediately before drug treatment of mice (control groups) or $2 \mathrm{~h}$ after treatment (test group). Aedes mosquitoes were fed on P. gallinaceum infected chickens (control groups) immediately before or after drug-treatment (test groups). Mosquito midguts 
were evaluated for two parameters: (a) the presence of oocysts and (b) the number of oocysts per mosquito, as compared to the control mosquito groups fed on the same animal immediately before drug treatment (considered as $100 \%)$. Thus, the effect of PQ and the test compounds on both prevalence and intensity of infection could be quantified and compared. The infected mice or chickens were fed-upon by Anopheles or Aedes mosquitoes, respectively, before drug treatment (time $=0 \mathrm{~h}$ ) or after drug treatment ( $2 \mathrm{~h}$ in mice or $6 \mathrm{~h}$ in chickens). All animals (mice or chickens) after the mosquitoes fed on them were anaesthesized with acepromazine $2.5 \mathrm{mg} / \mathrm{kg}$ then sacrificed by cervical dislocation. The mosquito midgut infection was assessed 12 days later for $P$. berghei or 6-7 days later for $P$. gallinaceum. By comparing oocyst numbers in mosquitoes blood-fed on the same animal before and after drug administration, each animal served as its own control. In the $P$. berghei model, among the nine PQ-TZs tested, five (4b, 4c, 4g, 4m and 4o) completely inhibited oocyst formation. Four of these five active compounds were also active in the P. gallinaceum model (4c, 4g, $4 \mathrm{~m}$ and $4 \mathrm{o}$ ). In contrast to its strong activity in the rodent model, compound $4 \mathrm{~b}$ was not active in P. gallinaceum (Table 3 ). Compound $4 \mathrm{~m}$, the only one tested in lower doses ( 50 and $25 \mathrm{mg} / \mathrm{kg}$ ) significantly inhibited the sporogonic cycle $(\mathrm{p}<0.001)$ of P. gallinaceum (Fig. 3).

Table 3 Oocyst number of $P$. gallinaceum in Aedes and $P$. berghei in Anopheles. Mosquitoes were allowed to blood feed on the infected vertebrate hosts before and after treatment with primaquine derivatives ( $4 b$ to $4 p$ ) or primaquine (15 $\mathrm{mg} / \mathrm{kg}$ )

\begin{tabular}{lll}
\hline $\begin{array}{l}\text { Compound tested } \\
\text { (50 } \mathbf{~ g / k g )}\end{array}$ & $\begin{array}{l}\text { \% Aedes infected (\% } \\
\text { reduction) }\end{array}$ & $\begin{array}{l}\text { \% Anopheles infected } \\
\text { (\% reduction) }\end{array}$ \\
\hline $\mathbf{4 b}$ & $80(11 \%)$ & $0(100 \%)$ \\
$\mathbf{4 c}$ & $10(89 \%)$ & $0(100 \%)$ \\
$\mathbf{4 d}$ & $80(6 \%)$ & $86(4 \%)$ \\
$\mathbf{4 e}$ & $89(0 \%)$ & $\mathrm{NT}$ \\
$\mathbf{4 f}$ & $95(5 \%)$ & $\mathrm{NT}$ \\
$\mathbf{4 g}$ & $45(50 \%)$ & $0(100 \%)$ \\
$\mathbf{4 h}$ & $90(0 \%)$ & $86(0 \%)$ \\
$\mathbf{4 i}$ & $70(13 \%)$ & $\mathrm{NT}$ \\
$\mathbf{4 j}$ & $75(0 \%)$ & $\mathrm{NT}$ \\
$\mathbf{4 k}$ & $95(5 \%)$ & $\mathrm{NT}$ \\
$\mathbf{4 I}$ & $84(16 \%)$ & $\mathrm{NT}$ \\
$\mathbf{4 m}$ & $45(55 \%)$ & $0(100 \%)$ \\
$\mathbf{4 n}$ & $95(0 \%)$ & $71(30 \%)$ \\
$\mathbf{4 0}$ & $15(85 \%)$ & $0(100 \%)$ \\
$\mathbf{4 p}$ & $75(6 \%)$ & $86(0 \%)$ \\
Primaquine & $0(100 \%)$ & $0(100 \%)$ \\
\hline
\end{tabular}

The $\%$ reduction of sporogony was calculated in relation to the control mosquitoes blood fed on the same animal host immediately before treatment

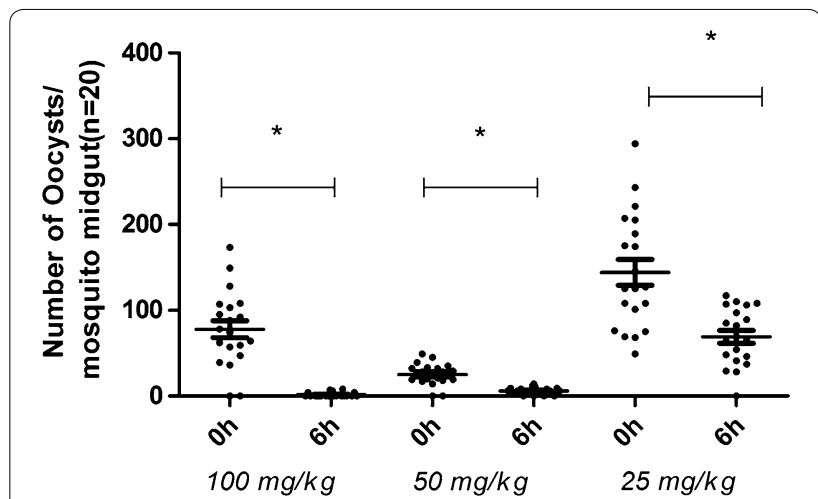

Fig. 3 Plasmodium gallinaceum oocyst numbers in midguts of Aedes fluviatilis. Mosquitoes fed on the same infected chicken at time $0 \mathrm{~h}$ (before treatment) or $6 \mathrm{~h}$ after treatment with compound $4 \mathrm{~m}$, which was administered orally. For each indicated time point, 20 mosquitoes were dissected. All doses significantly reduced oocyst numbers $(p<0.001)$, calculated by Mann-Whitney test

\section{Inhibition of the exoerythrocytic stage development in vitro and in vivo}

Anti-malarial drugs are designed to target the symptomatic blood stages, usually not exhibiting activity against exoerythrocytic parasites. PQ does eliminate the liver stage parasites [1] and is the only licensed drug that eliminates hypnozoites, the dormant liver stages of $P$. vivax. Selected PQ-TZs were tested for their ability to inhibit the $P$. berghei early exoerythrocytic form (EEF) development in vivo, the only EEF available for tests at our laboratories.

Five mice were used per group. They were treated by oral route for three consecutive days $(50 \mathrm{mg} / \mathrm{kg}$ per day) with PQ-TZ 4f, 4h, 4i, 4j, 4n and $4 \mathrm{~m}$, then they were inoculated by intravenous route with freshly isolated sporozoites and $42 \mathrm{~h}$ later their parasite liver load (EEF) was evaluated. The animals were anaesthetized with acepromazine $2.5 \mathrm{mg} / \mathrm{kg}$ then sacrificed by cervical dislocation, their livers were harvested and the parasites measured by real time PCR. As shown in Fig. 4, compound $4 \mathrm{~m}$ reduced the liver parasite burden by $95 \%$ in comparison with untreated controls. Nonetheless, PQ was more active, inhibiting liver parasite burden by 75, 93 and $99 \%$, at lower doses $(3.2,7.5$ and $15 \mathrm{mg} / \mathrm{kg}$ respectively). The other compounds were inactive (Additional file 1).

To determine whether the decrease in liver EEF seen in PQ-TZ $4 \mathrm{~m}$ treated mice was due to fewer parasites becoming mature exoerythrocytic stages or to all parasites being unable to complete liver stage development, mice were inoculated with $P$. berghei sporozoites and treated with PQ or PQ-TZ 4m. All mice were followed for development of the blood stage infection. Blood 
smears prepared on day 3 post sporozoite infection, until day 15, had their parasitaemia determined in Giemsastained thin smears. Complete protection is defined as the absence of parasites in blood smears for 2 weeks post-challenge with sporozoites. The onset of blood stage parasitaemia in mice treated with PQ-TZ 4m was delayed by 3 days, compared to untreated controls. This result indicates that PQ-TZ $4 \mathrm{~m}$ reduced but did not completely inhibit the development of infectious liver stage parasites and that some hepatic EEF were still able to initiate a blood stage infection. Nonetheless, this 3-day delay suggests that the sporozoite load was reduced by at least 100 -fold. Consequently, PQ-TZ $4 \mathrm{~m}$ treated mice also showed increased survival compared to controls (Fig. 5a, b). All five animals treated with PQ survived until the end of the experiment, when they were anesthetized with acepromazine $2.5 \mathrm{mg} / \mathrm{kg}$ and then sacrificed by cervical dislocation. Six mice were euthanized before the end of the experiment soon after malaria symptoms appeared: four non-treated control mice were euthanized on day 7 and 1 on day 9 post-infection, and one treated with PQ-TZ $4 \mathrm{~m}$ was euthanized on day 8 due to appearance of malaria symptoms. Mice were anaesthetized with acepromazine $2.5 \mathrm{mg} / \mathrm{kg}$ and then sacrificed by cervical dislocation. The other mice survived until the end of the experiment and did not present malaria symptoms.

We then used hepatocyte cultures to determine whether PQ-TZ 4m gave rise to fewer or smaller EEFs in vitro. Hepatoma cultures infected with 10,000 $P$. berghei sporozoites (ANKA strain) were incubated with different concentrations of $4 \mathrm{~m}$ for 2 days, at which point cultures were fixed and EEFs stained, counted and measured. The compound PQ-TZ $4 \mathrm{~m}$ at $1 \mu \mathrm{M}$ significantly inhibited both the number of $P$. berghei EEFs and their size, in agreement with the in vivo results (Fig. 6).

\section{Discussion}

PQ is used to prevent $P$. vivax relapses and to block malaria transmission. However, the toxicity of the PQ metabolites, especially the haemolytic activity to G6PDdeficient erythrocytes [20], limits its use in humans. Furthermore, primaquine causes gastrointestinal disorders
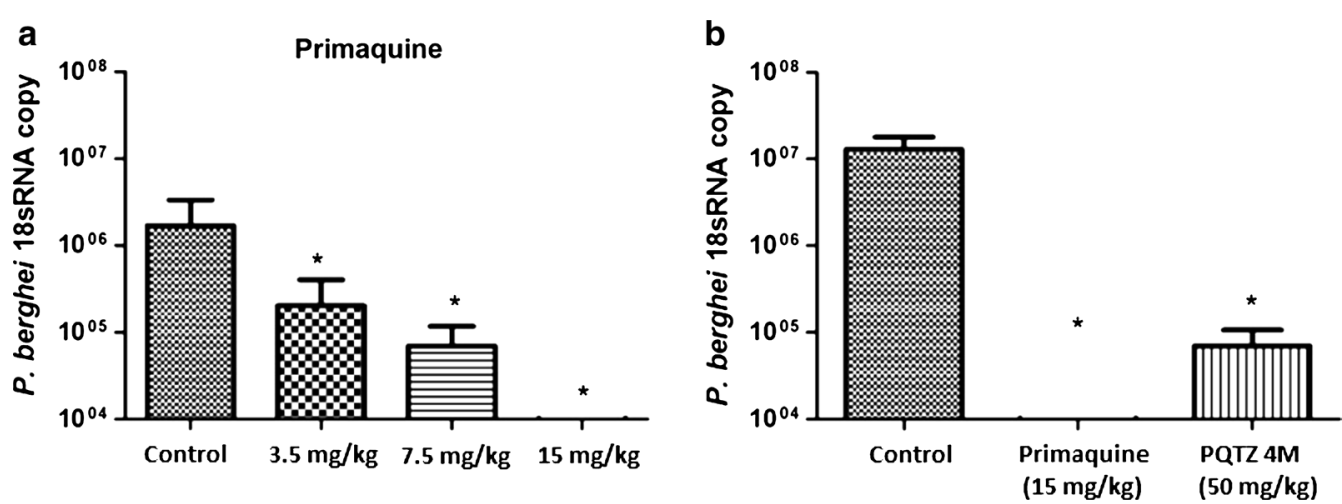

Fig. 4 Plasmodium berghei liver parasite burden $42 \mathrm{~h}$ after intravenous inoculation with sporozoites. Parasite numbers at $42 \mathrm{~h}$ post inoculation were measured by quantitative PCR in mice treated with PQ (a) or PQ-TZ 4m (b). ${ }^{*} p<0.05$ by Mann-Whitney test
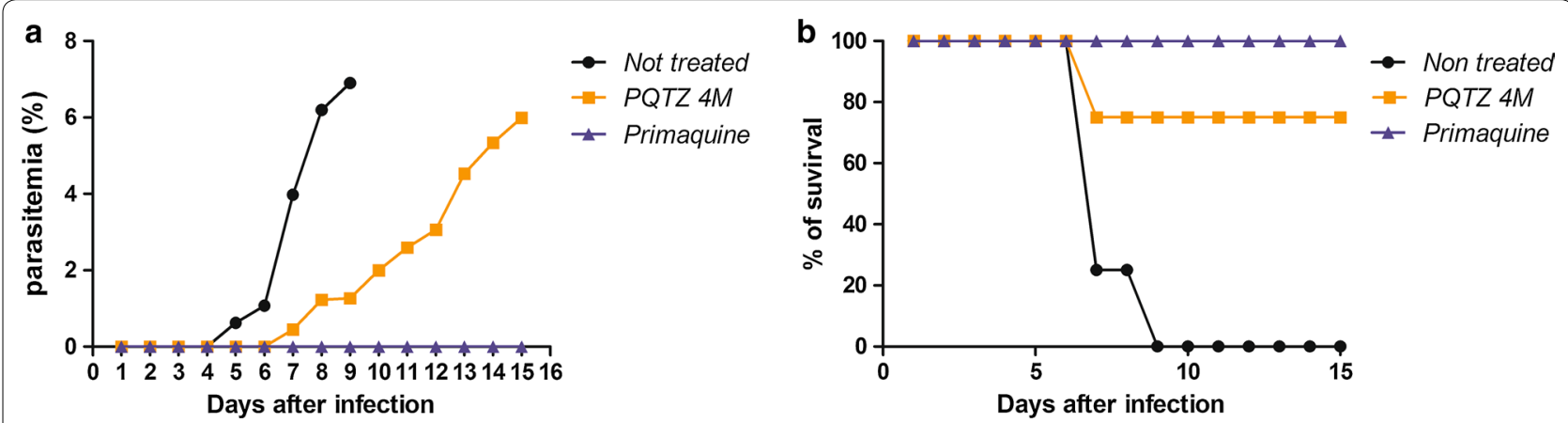

Fig. 5 Effect of PQ-TZ on parasite burden and survival of infected mice. Mice ( 5 per group) were treated with PQ-TZ $\mathbf{4 m}(50 \mathrm{mg} / \mathrm{kg})$ or primaquine $(15 \mathrm{mg} / \mathrm{kg})$, or not treated prior to inoculation of 10,000 P. berghei sporozoites. Mice parasitaemia was followed by blood smears (a) as well as survival (b) for 15 days (a) 
such as nausea, dizziness, and vomiting in both normal and G6PD deficient patients. Hypersensitivity reactions can also occur but are rare [20]. Tafenoquine is a candidate to replace PQ that has been evaluated in clinical trials. Tafenoquine was active in a single dose but it was also haemolytic for erythrocytes in G6PD-deficient patients [21,22].

The role of G6PD in red cells is to provide reductive potential in the form of NADPH [23]. In G6PD-deficient red cells, the NADPH supply is adequate in the steady state but falls short upon exposure to $\mathrm{PQ}$. It is possible that the PQ metabolite causes an oxidative challenge that the G6PD normal red cells would tolerate, but not the G6PD-deficient red cells. However, the stepwise sequence of the events from oxidative attack to haemolysis has not been fully elucidated [24].

Aiming to decrease malaria transmission, patients with malaria, regardless of the parasite species diagnosed, receive a single dose of $\mathrm{PQ}(0.75 \mathrm{mg} / \mathrm{Kg})$ orally to prevent malaria transmission to mosquitoes [4, 25]. The primary motivation for the present work was to study the toxicity and anti-parasite activity of PQ-TZ derivatives using rodent and avian malaria species. Pharmacokinetic studies in humans showed that carboxy-PQ is the main PQ metabolite, a compound less active than PQ [26]. The modification on the terminal amino group of PQ improved the PQ-TZs bioavailability by blocking this metabolism. Pro-drugs of PQ [27, 28], double-drugs $[29,30]$ and bis-PQ [31] have been studied to prevent this metabolism, as well as to reduce its toxicity in patients who are G6PD deficient. Some PQ analogues were also synthesized as PQ-trioxaquines [30] and the chemical and enzymatic stable PQ-imidazolidinones [32, 33] (Fig. 1b), a novel type of 8-aminoquinoline anti-malarial agents.

Diverse biological activities have been described for heterocyclic thiazolidinones, including antimicrobial
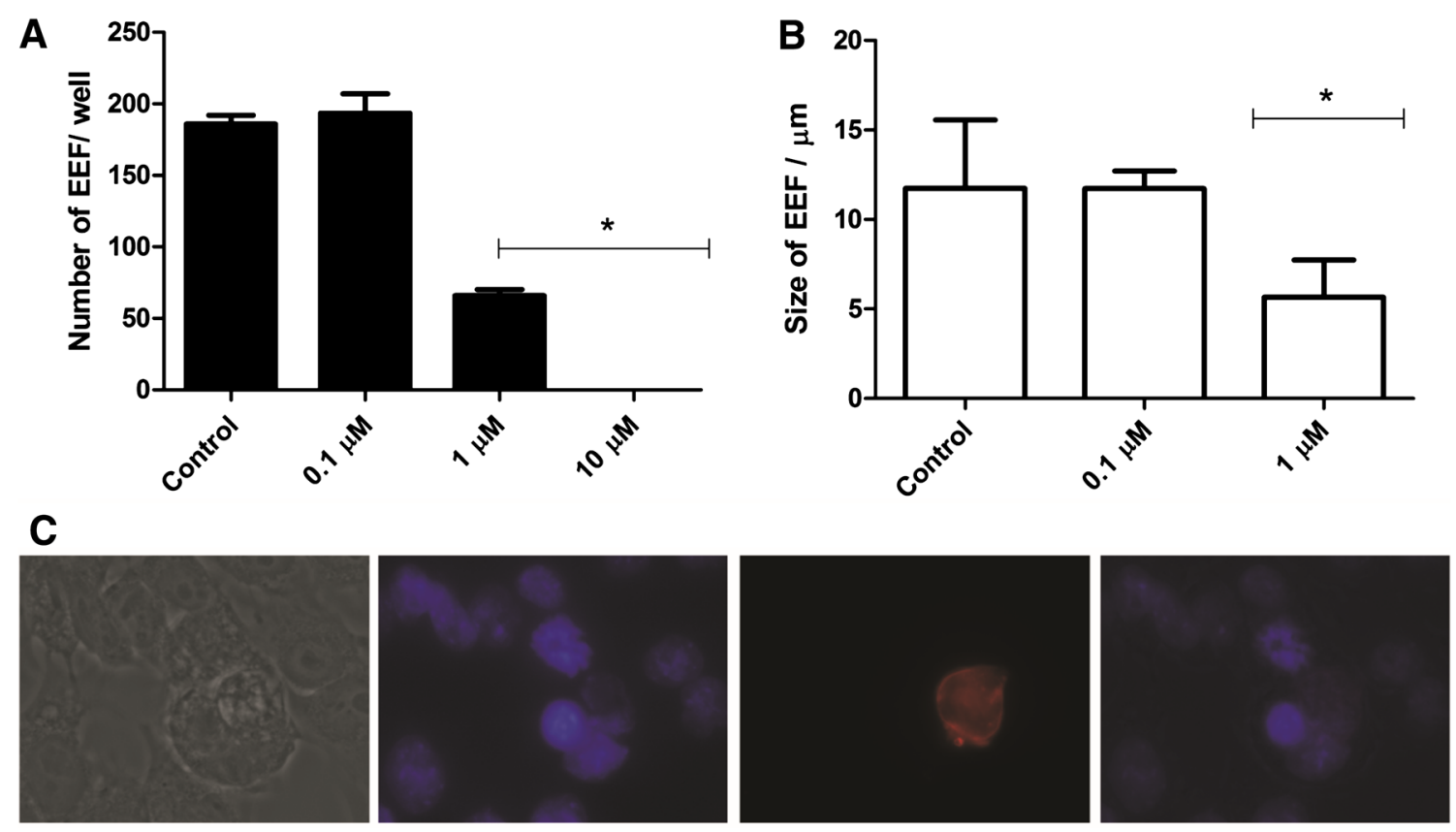

D

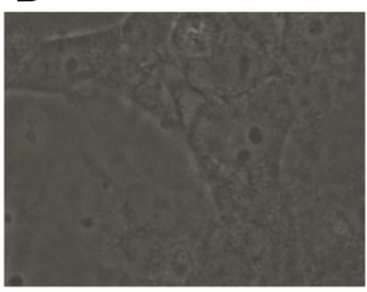

Phase

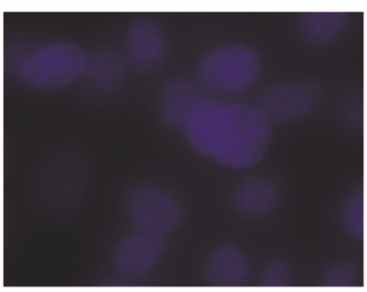

DAPI

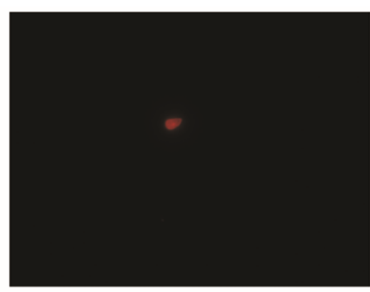

3D11

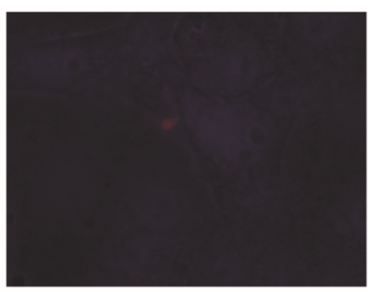

Overlay

Fig. 6 Effect of PQ-TZ 4m on infected hepatocytes in vitro. Number (a) and size (b) of the exoerythrocytic forms of P. berghei (EEF) in cultures of mouse hepatocytes (cell line Hepa1-6), in the presence of compound PQ-TZ $\mathbf{4 m}$ at 0.1, 1 and $10 \mu \mathrm{M}$ concentrations. Representative EEFs in control (c) or $10 \mu \mathrm{M} \mathrm{PQ-TZ} \mathrm{4m-treated} \mathrm{Hepa1-6} \mathrm{cells} \mathrm{(d).} \mathrm{The} \mathrm{same} \mathrm{image} \mathrm{is} \mathrm{shown} \mathrm{for} \mathrm{each} \mathrm{in} \mathrm{phase,} \mathrm{stained} \mathrm{with} \mathrm{DAPI,} \mathrm{and,} \mathrm{stained} \mathrm{with} \mathrm{mAb} \mathrm{3D11}$ against the developing EEF. ${ }^{* *} \mathrm{p}<0.05$ by Mann-Whitney test. Need size bars 
[34, 35], anti-fungal [36], anti-inflammatory [37], antitumour [38], anti-HIV [39], anti-Alzheimer's disease as muscarinic receptor 1 agonist [40], and anti-malarial [41]. As for PQ-imidazolidinone derivatives, PQ-TZs are unlikely to act as pro-drugs because the thiazolidin-4-one ring is stable at low $\mathrm{pH}$. A simple test consisting of addition of concentrated chloridric acid $(1 \mathrm{~mL})$ to PQ-TZs $\left(50 \mathrm{mg}\right.$ ) at $40{ }^{\circ} \mathrm{C}$ for 24 and $48 \mathrm{~h}$ showed the stability of PQ-TZs. Moreover, by blocking the amino free group, PQ-TZs compounds may prevent the formation of cyclic pyrrolidine [42]. Indeed, as opposed to PQ, several PQTZs were tested in vitro on G6PD deficient and normal human erythrocytes and caused no haemolysis (Table 2).

Several reports have described the protection of the quinoline ring at the 5 position, to avoid the formation of the toxic 5-hydroxy-PQ metabolite [27, 43-45]. Although the structure of PQ-TZs does not directly influence the 5-position of the quinoline ring, 5-hydroxy-PQ-TZ might be formed. However, others report that the modification of primary amino group decreases toxicity through unknown mechanisms [45]. Indeed, most of PQ-TZs tested were significantly less toxic than PQ against human hepatoma and monkey kidney cells in vitro, as well as to normal and G6PD deficient human erythrocytes.

There is no significant influence of the nature of the aryl substituent on the ability of PQ-TZs to inhibit Plasmodium sporogony in the mosquito host. However, the 4-position seems to be important for drug activity. Accordingly, this position was substituted in three of the four most active compounds (4g, 4m and 4o) (Table 3), with compound $4 \mathrm{~g}$ resulting more toxic than $4 \mathrm{~m}$ and $4 \mathrm{o}$. The compound $4 \mathrm{~m}$, which contains a methoxy group, inhibited Plasmodium sporogony at a lower dose of $25 \mathrm{mg} / \mathrm{kg}$; the other compounds were not tested at lower doses.

In spite of the irregular production of oocysts observed in all malaria models [46], there were statistically significant differences among the groups of mosquitoes blood-fed in animals pre-treated with the compounds considered active (4c, 4g, $4 \mathrm{~m}$ and $4 \mathrm{o}$ ). Although none of the compounds tested completely inhibited oocyst formation in P. gallinaceum, 4b, 4c, 4g, 4m and $4 \mathrm{o}$ inhibited oocyst formation of $P$. berghei in Anopheles mosquitoes, as did PQ tested in parallel in both models. One possibility to explain these results is a different PQ-TZs metabolism in mammals versus avian hosts, making the mouse model more efficient at detecting active compounds. Nevertheless, in both models PQ caused 100\% inhibition of sporogony.

All active compounds in the mice model were less inhibitory against the bird malaria parasites, or they caused a lower inhibition of the oocyst prevalence. These overall results could also be explained by the longer period of time elapsed between drug administration to the chicken and the mosquitoes blood meal of 4-6 $\mathrm{h}$ compared to $2 \mathrm{~h}$ in the mice model. New studies have shown that Plasmodium yoelii nigeriensis is a viable model system to study malaria transmission by the New World vectors Anopheles aquasali and Anopheles albimanus [47]. However, the differences between mammal and avian models need to be better understood, especially because of the limitation of a good Anopheles vector for infect mice in Brazil, therefore limiting the mosquito work to the P. gallinaceum model in Brazil.

One PQ-TZ derivative $(4 \mathrm{~m})$ inhibiting sporogony, also inhibited development of $P$. berghei liver stages in vitro ( $1 \mu \mathrm{M}$ dose), and in vivo; a result which makes the chemical group valuable. The ability of $4 \mathrm{~m}$ to destroy the hypnozoites of $P$. vivax, as does $\mathrm{PQ}$, has yet to be determined.

\section{Conclusions}

The main findings described here include: (i) all the 15 PQ-TZs tested were not toxic to mammalian cells in vitro, unlike $P Q$, nor to mice treated with high doses of the new drugs; (ii) the PQ-TZs caused no direct haemolysis to human RBCs deficient or not in the enzyme G6PD; (iii) most PQ-TZs displayed a lower toxicity than PQ to mammalian cell lines - human hepatoma cells and kidney cells from green monkey; (iv) compounds 4b, 4c, $4 \mathrm{~g}, 4 \mathrm{~m}$ and $4 \mathrm{o}$ completely blocked the malaria sporogonic cycle of $P$. berghei in An. stephensi mosquitoes compared to the control mosquitoes blood-fed in the same animal immediately prior to drug treatment; (v) four PQ-TZs (4c, $4 \mathrm{~g}, 4 \mathrm{~m}$ and $4 \mathrm{o}$ ) administered to chickens experimentally infected with $P$. gallinaceum also inhibited the sporogonic cycle by $50-90 \%$ in Aedes mosquitoes bloodfed after drug treatment; (vi) compound $4 \mathrm{~m}$ reduced $P$. gallinaceum sporogony at lower doses of 50 and $25 \mathrm{mg} /$ $\mathrm{kg}$; (vi) compound $4 \mathrm{~m}$ reduced the number of EEFs in hepatoma cells and in mice; (vii) compound $4 \mathrm{~m}$ also caused a 3-day delay in the malaria pre-patent period. Whether these active PQ-TZs will become promising new drugs to help malaria control is an open question that requires further pharmacological studies and tests against the hypnozoite forms aiming to cure the $P$. vivax late relapses.

\section{Additional file}

Additional file 1: Table S1. Inhibition of Plasmodium gallinaceum sporogony by PQ-TZ derivatives in Aedes mosquitoes blood fed $6 \mathrm{~h}$ after oral treatment $(6 \mathrm{~h}$ ) with one compound dose in relation to control mos quitoes fed in the same chicken before treatment (0 h). Table S2. Inhibition of Plasmodium berghei sporogony by PQ-TZ derivatives in Anopheles mosquitoes blood fed $2 \mathrm{~h}$ after oral treatment ( $2 \mathrm{~h}$ ) with one dose of each compound in relation to mosquitoes blood fed in the mouse before drug treatment (0 h). Figure S1. Plasmodium berghei liver parasite burden $42 \mathrm{~h}$ after intravenous inoculation with sporozoites, measured by quantitative PCR in mice treated with PQ-TZ. 


\section{Abbreviations}

BGM: kidney cell line from Buffalo Green Monkey Kidney; EEFs: exoerythrocytic forms; G6PD: glucose-6-phosphate dehydrogenase; HEPA 1-6: mouse hepatocyte cell line; HepG2: human hepatoma cell line; $\mathrm{MDL}_{50}$ : drug concentration that killed $50 \%$ of the cells; PQ: primaquine; PQ-TZs: primaquine derivatives; Tz: thiazolidinones.

\section{Authors' contributions}

ACCA, FJBF, PS, FZ and AUK designed, analysed and interpreted the biological experiments. BBD, PDN and WC synthesized the compounds studied. TK provided red blood cells from G6PD deficient donors. ACCA, WC, PS, FZ and AUK wrote the manuscript. All authors read and approved the final manuscript.

\section{Author details}

${ }^{1}$ Centro de Pesquisas René Rachou-Fiocruz, Av. Augusto de Lima 1715, Belo Horizonte, MG 30190-002, Brazil. ${ }^{2}$ Faculdade de Medicina, Universidade Federal de Minas Gerais, Av. Alfredo Balena, 190, Belo Horizonte, MG 30130-100, Brazil. ${ }^{3}$ Department of Molecular Microbiology and Immunology, Johns Hopkins Bloomberg School of Public Health, 615 N Wolfe St., Baltimore, MD 21205, USA. ${ }^{4}$ Laboratório de Química Aplicada à Bioativos, Centro de Ciências Químicas, Farmacêuticas e de Alimentos, UFPel, Campus Universitário s/ no, Pelotas, RS 98001-970, Brazil. ${ }^{5}$ Laboratório de Epidemiologia, Fundação Osvaldo Cruz-Fiocruz Rondônia, Bairro Lagoa, Porto Velho, RO, Brazil.

\section{Acknowledgements}

We thank Dr. Luciano Moreira (FIOCRUZ-Minas) for the insectary facilities, and to the Bloomberg Family Foundation for their support of the Insectary facilities and Parasitology Core Facilities at the Johns Hopkins Malaria Research Institute (JHMRI).

\section{Competing interests}

The authors declare that they have no competing interests.

\section{Availability of data and materials}

All data generated or analysed during this study are included in this published article [and its supplementary information files].

\section{Funding}

This work had financial support from the Conselho Nacional de Pesquisas e Desenvolvimento (CNPq) Edital MCT/CNPq 09/2009 PRONEX, Rede de Malária (305314/2009-2), MCT/CNPq/CT/MS/SCTIE/DECIT 034/2008 (575746/2008-4), and Fundação de Amparo a Pesquisa de Minas Gerais-FAPEMIG (Universal CBB-APQ-01692-11; and PRONEX Rede Malária). CNPq also provided fellowships to the authors (AUK, ACCA, FJBF, WC, and BBD); The Universidade Federal de Pelotas and CAPES provided fellowships to PDN. The work was also supported by NIH grant R01AI056840 (PS).

\section{Received: 12 October 2016 Accepted: 26 February 2017}

Published online: 09 March 2017

\section{References}

1. WHO. World malaria report 2015. Geneva: World Health Organization; 2015. http://www.who.int/malaria/publications/world_malaria_report/ en/.

2. Ministério da Saúde. http://bvsms.saude.gov.br/bvs/publicacoes/guia_ pratico_malaria.pdf.

3. Baird JK, Hoffman SL. Primaquine therapy for malaria. Clin Infect Dis. 2004;39:1336-45.

4. WHO. Global malaria programme. Global plan for artemisinin resistance containment (GPARC). Geneva: World Health Organization; 2011. http:// www.who.int/malaria/publications/atoz/artemisinin_resistance_containment_2011.pdf. Accessed Feb 2017

5. Carmona-Fonseca J, Alvarez G, Maestre A. Methemoglobinemia and adverse events in Plasmodium vivax malaria patients associated with high doses of primaquine treatment. Am J Trop Med Hyg. 2009;80:188-93.

6. Vale N, Moreira R, Gomes P. Primaquine revisited six decades after its discovery. Eur J Med Chem. 2009;44:937-53.
7. Tripathi AC, Gupta SJ, Fatima GN, Sonar PK, Verma A, Saraf SK. 4-Thiazolidinones: the advances continue. Eur J Med Chem. 2014;72:52-77.

8. Solomon VR, Haq W, Srivastava K, Puri SK, Katti SB. Synthesis and antimalarial activity of side chain modified 4-aminoquinoline derivatives. J Med Chem. 2007:50:394-8.

9. Neuenfeldt PD, Drawanz BB, Aguiar ACC, Figueiredo JF, Krettli AU, Cunico W. Multicomponent synthesis of new primaquine thiazolidinone derivatives. Synthesis. 2011;23:3866-70.

10. Katsuragawa TH, Gil LHS, Stábile RG, Pires MG, Bonini-Domingos CR. Avaliação da incidência da deficiência de Glicose-6-Fosfato Desidrogenase (G6PD) e perfil hematológico em indivíduos de uma região de Rondônia. Rev Bras Hematol Hemoter. 2004;26:268-73.

11. Madureira MC, Martins AP, Gomes M, Paiva J, Proença da Cunha A, et al. Antimalarial activity of medicinal plants used in traditional medicine in Sao Tomé and Príncipe islands. J Ethnopharmacol. 2002;8:23-9.

12. Bézivin C, Tomasi S, Lohézic-Le FD, Boustie J. Cytotoxic activity of some lichen extracts on murine and human cancer cell lines. Phytomedicine. 2003:10:499-503.

13. Lorke D. A new approach to practical acute toxicity testing. Arch Toxicol. 1983:54:275-87.

14. Gwadz RW, Koontz LC, Miller LH, Davidson DE. Plasmodium gallinaceum: avian screen for drugs with radical curative properties. Exp Parasitol. 1983;55:188-96.

15. Carvalho LH, Ferrari WM, Krettli AU. A method for screening drugs against the liver stages of malaria using Plasmodium gallinaceum and Aedes mosquitoes. Braz J Med Biol Res. 1992;25:247-55.

16. Sinnis P, Vega PDL, Coppi A, Krzych U, Mota MM. Quantification of sporozoite invasion, migration, and development by microscopy and flow cytometry. Methods Mol Biol. 2013:923:385-400.

17. Bruña-Romero O, Hafalla JC, González-Aseguinolaza G, Sano G, Tsuji M, Zavala F. Detection of malaria liver-stages in mice infected through the bite of a single Anopheles mosquito using a highly sensitive real-time PCR. Int J Parasitol. 2001:31:1499-502.

18. Wang C, Qin X, Huang B, He F, Zeng C. Hemolysis of human erythrocytes induced by melamine-cyanurate complex. Biochem Biophys Res Commun. 2010;402:773-7.

19. Brewer GJ, Tarlov AR, Kellermeyer RW, Alving AS. The hemolytic effect of primaquine. XV. Role of methemoglobin. J Lab Clin Med. 1962;59:905-17.

20. Hill DR, Baird JK, Parise ME, Lewis LS, Ryan ET, Magill AJ. Primaquine: report from CDC expert meeting on malaria chemoprophylaxis I. Am J Trop Med Hyg. 2006;75:402-15.

21. Walsh DS, Eamsila C, Sasiprapha T, Sangkharomya S, Khaewsathien P, Supakalin $\mathrm{P}$, et al. Efficacy of monthly tafenoquine for prophylaxis of Plasmodium vivax and multidrug-resistant $P$. falciparum malaria. J Infect Dis. 2004;190:1456-63.

22. Ebstie YA, Abay SM, Tadesse WT, Ejigu DA. Tafenoquine and its potential in the treatment and relapse prevention of Plasmodium vivax malaria: the evidence to date. Drug Des Dev Ther. 2016:26(10):2387-99.

23. Hohl RJ, Kennedy EJ, Frischer H. Defenses against oxidation in human erythrocytes: role of glutathione reductase in the activation of glucose decarboxylation by hemolytic drugs. J Lab Clin Med. 1991;117:325-31.

24. Luzzatto L, Seneca E. G6PD deficiency: a classic example of pharmacogenetics with on-going clinical implications. Br J Haematol. 2014;164:469-80.

25. Santana MS, de Lacerda MV Barbosa MD, Alecrim WD, Alecrim MD. Glucose-6-phosphate dehydrogenase deficiency in an endemic area for malaria in Manaus: a cross-sectional survey in the Brazilian Amazon. PLoS ONE. 2014:4:5259.

26. Mihaly GW, Ward SA, Edwards G, Orme MLE, Breckenridge AM. Pharmacokinetics of primaquine in man: identification of the carboxylic acid derivative as a major plasma metabolite. $\mathrm{Br} J$ Clin Pharmacol. 1984;17:441-6.

27. Vangapandu S, Sachdeva S, Jain M, Singh S, Singh PP, Kaul CL, et al. 8-quinolinamines and their pro prodrug conjugates as potent bloodschizontocidal antimalarial agents. Bioorg Med Chem. 2003;11:4557-68.

28. Mata G, Rosário VE, lley J, Constantino L, Moreira R. A carbamate-based approach to primaquine prodrugs: antimalarial activity, chemical stability and enzymatic activation. Bioorg Med Chem. 2012;15:886-92.

29. Dell'Agli M, Parapini S, Galli G, Vaiana N, Taramelli D, Sparatore A, et al. High antiplasmodial activity of novel plasmepsins I and II inhibitors. J Med Chem. 2006:49·7440-9. 
30. Romeo S, Dell'Agli M, Parapini S, Rizzi L, Galli G, Mondani M, et al. Plasmepsin II inhibition and antiplasmodial activity of primaquine-statine 'double-drugs'. Bioorg Med Chem Lett. 2004;14:2931-4.

31. Kaur K, Jain M, Khan SI, Jacob MR, Tekwani BL, Singh S, et al. Synthesis, antiprotozoal, antimicrobial, $\beta$-hematin inhibition, cytotoxicity and methemoglobin (MetHb) formation activities of bis(8-aminoquinolines). Bioorg Med Chem. 2011;19:197-210.

32. Dechy-Cabaret O, Benoit-Vical F, Loup C, Robert A, Gornitzka H, Bonhoure A, et al. Synthesis and antimalarial activity of trioxaquine derivatives. Chem Eur J. 2004;10:1625-36.

33. Araújo MJ, Bom J, Capela R, Casimiro C, Chambel P, Gomes P, et al. Imidazolidin-4-one derivatives of primaquine as novel transmission-blocking antimalarials. J Med Chem. 2005;48:888-92.

34. Vale N, Matos J, Gut J, Nogueira F, Rosario V, Rosenthal PJ, et al. Imidazolidin-4-one peptidomimetic derivatives of primaquine: synthesis and antimalarial activity. Bioorg Med Chem Lett. 2008;18:4150-3.

35. Chawla P, Singh R, Saraf SK. Syntheses and evaluation of 2,5-disubstituted 4-thiazolidinone analogues as antimicrobial agents. Med Chem Res. 2012;21:2064-71.

36. Kunzler A, Neuenfeldt PD, das Neves AM, Pereira CMP, Marques GH, Nascente PS, et al. Synthesis, antifungal and cytotoxic activities of 2-aryl3-((piperidin-1-yl)ethyl)thiazolidinones. Eur J Med Chem. 2013;64:74-80.

37. Maccari R, Vitale RM, Ottanà R, Rocchiccioli M, Marrazzo A, Cardile V, et al. Structure-activity relationships and molecular modelling of new 5-arylidene-4-thiazolidinone derivatives as aldose reductase inhibitors and potential anti-inflammatory agents. Eur J Med Chem. 2014;81:1-14.

38. Isloor AM, Sunil D, Shetty P, Malladi S, Pai KSR, MaliyakkI N. Synthesis, characterization, anticancer, and antioxidant activity of some new thiazolidin4-ones in MCF-7 cells. Med Chem Res. 2013;22:758-67.

39. Tian Y, Zhan P, Rai D, Zhang J, De Clercq E, Liu X. Recent advances in the research of 2,3-diaryl-1,3-thiazolidin-4-one derivatives as potent
HIV-1 non-nucleoside reverse transcriptase inhibitors. Curr Med Chem. 2012;19:2026-37.

40. Malviya M, Kumar YCS, Mythri RB, Venkateshappa C, Subhash MN, Rangappa KS. Muscarinic receptor 1 agonist activity of novel $\mathrm{N}$-aryl carboxamide substituted 3-morpholino arecoline derivatives in Alzheimer's presenile dementia models. Bioorg Med Chem. 2009;17:5526-34.

41. Solomon VR, Haq W, Srivastava K, Puri SK, Katti SB. Synthesis and antimalarial activity of side chain modified 4-aminoquinoline derivatives. J Med Chem. 2017;50:394-8.

42. Pybus BS, Sousa JC, Jin X, Ferguson JA, Christian RE, Barnhart R, et al. CYP450 phenotyping and accurate mass identification of metabolites of the 8-aminoquinoline, anti-malarial drug primaquine. Malar J. 2012;11:259.

43. LaMontagne MP, Blumbergs P, Strube RE. Antimalarials. 14. 5-(Aryloxy)4-methylprimaquine analogues. A highly effective series of blood and tissue schizonticidal agents. J Med Chem. 1982;25:1094-7.

44. Chen EH, Tanabe K, Saggiomo AJ, Nodiff EA. Modifications of primaquine as antimalarials. 4. 5-alkoxy derivatives of primaquine. J Med Chem. 1987;30:1193-9.

45. Philip A, Kepler JA, Johnson BH, Carroll FI. Peptide derivatives of primaquine as potential antimalarial. Agents J Med Chem. 1988;31:870-4.

46. Vega-Rodríguez J, Ghosh AK, Kanzok SM, Dinglasan RR, Wang S, Bongio $\mathrm{NJ}$, et al. Multiple pathways for Plasmodium ookinete invasion of the mosquito mid-intestine. Proc Natl Acad Sci USA. 2014;111:E492-500.

47. Orfano AS, Duarte AP, Molina-Cruz A, Pimenta PF, Barillas-Mury C. Plasmodium yoelii nigeriensis (N67) is a robust animal model to study malaria transmission by South American Anopheline mosquitoes. PLoS ONE. 2016;11:e0167178.

\section{Submit your next manuscript to BioMed Central and we will help you at every step:}

- We accept pre-submission inquiries

- Our selector tool helps you to find the most relevant journal

- We provide round the clock customer support

- Convenient online submission

- Thorough peer review

- Inclusion in PubMed and all major indexing services

- Maximum visibility for your research

Submit your manuscript at www.biomedcentral.com/submit
() BioMed Central 